\title{
Anatomia do caule de Serjania corrugata Radlk. (Sapindaceae) ${ }^{1}$
}

\author{
Gabriel Uriel Cruz Araújo ${ }^{2,3}$ e Cecilia Gonçalves Costa ${ }^{2}$
}

Recebido em 26/06/2006. Aceito em 12/11/2006

\begin{abstract}
RESUMO - (Anatomia do caule de Serjania corrugata Radlk. (Sapindaceae)). A estrutura anatômica do caule adulto de S. corrugata foi detalhada, com o objetivo de contribuir para a identificação de caules de lianas usadas comercialmente. São destacadas as seguintes características: variação cambial do tipo massa xilemática dividida, dimorfismo vasal, faixas de parênquima não-lignificado no lenho, placas de perfuração simples, séries cristalíferas no xilema e floema secundários, placas crivadas simples, anel de esclerênquima no floema não-condutor e mensurações dos elementos celulares do lenho.
\end{abstract}

Palavras-chave: Serjania, lianas, variação cambial, crescimento secundário anômalo

\begin{abstract}
Stem anatomy of Serjania corrugata Radlk. (Sapindaceae)). The anatomical structure of the adult stem of S. corrugata is described to assist in the identification of liana stems used commercially. The main features are as follows: cambial variant of the divided- xylem-mass type, vessel dimorphism, non-lignified parenchyma bands in the wood, simple perforation plates, crystalliferous series in secondary xylem and phloem, simple sieve plates, sclerenchyma ring in the non-conducting phloem and measurements of xylem cells.
\end{abstract}

Key words: Serjania, lianas, cambial variant, anomalous secondary growth

\section{Introdução}

As lianas (trepadeiras lenhosas) são uma das formas de vida mais comuns em ecossistemas tropicais (Bamber \& Ter Welle 1994), podendo representar até $30 \%$ das espécies de uma floresta (Putz 2006). Entretanto, as lianas são pouco estudadas, especialmente em relação à sua estrutura anatômica, se comparadas a plantas de outros hábitos. Este fato provavelmente se deve à maior importância comercial das árvores, e à dificuldade de coleta e identificação das lianas (Putz 2006).

As lianas constituem uma importante fonte de estudos sobre variações cambiais (crescimento secundário anômalo), visto que tais variações ocorrem com maior frequiência entre elas (Metcalfe 1983; Carlquist 1991). Alguns tipos de variação cambial são únicos para a família Sapindaceae, como o tipo massa xilemática dividida (Metcalfe \& Chalk 1950; Metcalfe 1983; Acevedo-Rodríguez 1991; 1993). Este tipo é característico do "grupo de S. paradoxa" sensu Acevedo-Rodríguez (1991), que compreende oito espécies de Serjania, entre as quais está incluída S. corrugata Radlk. (Acevedo-Rodríguez \& Somner 2001).

A família Sapindaceae está representada por 133 gêneros e aproximadamente 1.450 espécies, que se distribuem principalmente nos trópicos, ocorrendo raramente em regiões subtropicais e temperadas (Klaassen 1999). No Brasil, ocorrem 22 gêneros e 380 espécies, a maior parte destas localizadas na região amazônica (Barroso et al. 1991). O gênero Serjania conta com aproximadamente 226 espécies de lianas nativas de áreas tropicais e subtropicais do Novo Mundo (Acevedo-Rodríguez 1993), ocorrendo no Brasil cerca de 92 espécies, entre as quais 47 são endêmicas (Acevedo-Rodríguez 1990).

As Sapindaceae são utilizadas em ornamentação, produção de madeira para carpintaria, móveis e lenha; algumas espécies têm frutos comestíveis, como Litchi chinensis Sonn.; outras, possuem propriedades medicinais, como Paullinia cupana HBK, também conhecida pelo refresco de guaraná, muito popular no Brasil (Klaassen 1999; Guarim Neto et al. 2000).

\footnotetext{
Parte da dissertação de mestrado do primeiro Autor

2 Instituto de Pesquisas Jardim Botânico do Rio de Janeiro, Laboratório de Botânica Estrutural, Rua Pacheco Leão 915, 22460-030 Jardim Botânico, Rio de Janeiro, RJ, Brasil

3 Autor para correspondência: guc_araujo@yahoo.com.br
} 
Algumas espécies de Serjania e Paullinia popularmente conhecidas no Brasil como "timbó" e "tingüî́" possuem substâncias ictiotóxicas, usadas na pescaria (Guarim Neto et al. 2000).

Além disso, o caule de diversas lianas, especialmente daquelas espécies em que ocorrem variações cambiais, são usados em artesanato para adornar colares, brincos e objetos de madeira (caixas, porta-retratos, etc.). A descrição anatômica do caule das lianas é de fundamental importância na determinação de material estéril, o que torna possível a fiscalização e conservação desses recursos. O Instituto Brasileiro de Meio Ambiente e Recursos Naturais Renováveis (IBAMA) utiliza com sucesso a anatomia do lenho como ferramenta para identificação botânica de espécies arbóreas madereiras, quando o material encontra-se desprovido de ramos.

Este estudo tem por objetivo detalhar a estrutura anatômica do caule adulto de $S$. corrugata, a fim de contribuir para a sua identificação anatômica e, conseqüentemente, sua preservação.

\section{Material e métodos}

Os exemplares analisados de Serjania corrugata Radlk. foram procedentes do entorno do Jardim Botânico do Rio de Janeiro (Rio de Janeiro, RJ) e do Morro das Andorinhas, região Oceânica de Niterói, RJ. Foram feitas amostras do caule lenhoso, a cerca de 1,30 $\mathrm{m}$ da base, com o auxílio de um serrote. Tais amostras foram fixadas em FAA 50 e conservadas em álcool 70\% (Johansen 1940). O material testemunho encontra-se depositado no Herbário do Instituto de Pesquisas Jardim Botânico do Rio de Janeiro (RB), sob os números RB402689, RB402690 e RB402691, e as amostras do caule registrados na xiloteca da mesma instituição (RBw), sob os números RBw8489, RBw8490 e RBw8491.

As amostras foram submetidas ao processo de secagem em temperatura ambiente e, posteriormente, secionadas em micrótomo de deslize Leica. Parte das amostras foi secionada sem inclusão e parte emblocada em polietilenoglicol 1500 (Rupp 1964), sendo as seções obtidas coradas em Azul de Astra 1\% e Safranina 1\% (Bukatsck 1972, modificado por Kraus \& Arduin 1997), usando-se Permount para montagem das lâminas permanentes. Para mensuração dos elementos celulares, o xilema secundário foi dissociado e a seguir, corado com Safranina 1\%, segundo metodologia de Franklin, modificação de Kraus \& Arduin (1997), montando-se as lâminas semi-permanentes em glicerina 50\%. Testes histoquímicos foram realizados em seções de material recém-coletado, tendo sido o amido evidenciado pelo teste do lugol (Johansen 1940) e os cristais de oxalato de cálcio, pela insolubilidade no ácido acético concentrado e solubilidade no ácido clorídrico diluído (Strasburger 1924).

A descrição anatômica, contagem e mensuração dos elementos celulares do lenho obedeceram às normas do IAWA Committee (1989). Seguindo-se recomendação de Klaassen (1999), não foi calculada a média do diâmetro dos vasos. A terminologia utilizada para a descrição da casca obedecem às recomendações de Richter et al. (1996).

\section{Resultados}

O caule adulto de Serjania corrugata apresenta variação cambial do tipo massa xilemática dividida (Fig. 1), com cinco cilindros vasculares (compostos por xilema e floema secundários) dispostos radialmente, separados por regiões intermediárias, onde se observam células de parênquima e esclerênquima (Fig. 2).

O lenho apresenta porosidade difusa, com elementos de vaso de contorno circular a elíptico, que ocorrem em diâmetros diferentes - largos e estreitos, e intermediários em menor proporção (Fig. 3) - ocorrendo também traqueídes vasicêntricas (Fig. 8).

Os elementos de vaso largos apresentam-se solitários ou aos pares, raramente em grupos de três, organizados tangencialmente. Os elementos de vaso intermediários apresentam-se solitários. As placas de perfuração nos elementos largos e intermediários são simples e horizontais. Os elementos de vaso estreitos ocorrem em grupos radiais de até 20 elementos. Nestes, as placas de perfuração também são simples, situadas em paredes terminais oblíquas ou nas paredes laterais do elemento de vaso (Fig. 4). Alguns elementos de vaso estreitos apresentam paredes irregulares (Fig. 5-7). Podem ocorrer depósitos de uma substância de cor vermelho-alaranjada, não identificada pelos testes histoquímicos realizados.

As pontoações intervasculares são areoladas, simples ou guarnecidas, poligonais, em disposição alterna (Fig. 8); as pontoações raio-vasculares são morfologicamente semelhantes às intervasculares.

Ocorre parênquima axial paratraqueal escasso e apotraqueal em faixas tangenciais onduladas de 2-6 células, além de faixas de parênquima apotraqueal não lignificado (Fig. 3); presença de cristais prismáticos ou justapostos, em células de parênquima axial 

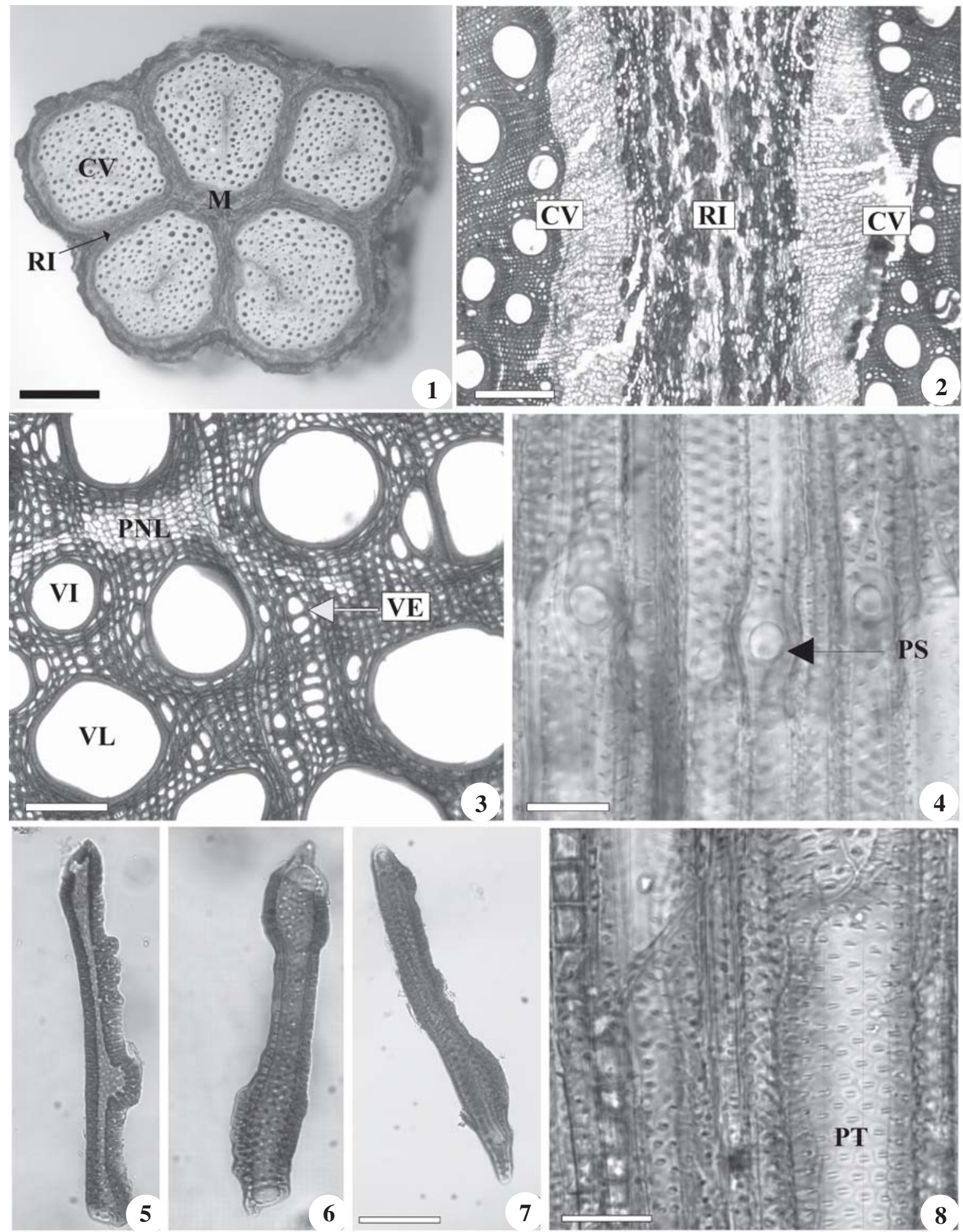

Figura 1. Caule adulto de Serjania corrugata Radlk., onde se observam cinco cilindros vasculares (CV) dispostos radialmente em torno da medula (M), separados por regiões intermediárias (RI). Figura 2. Seção transversal do caule, detalhando a região intermediária (RI) entre dois cilindros vasculares (CV), composta por células de parênquima e esclerênquima. Figura 3. Seção transversal do lenho, evidenciando ocorrência de elementos de vaso largos (VL) e intermediários (VI) preferencialmente solitários, elementos de vaso estreitos (VE) em cadeias radiais, e presença de faixas de parênquima não-lignificado (PNL). Figura 4. Seção longitudinal radial do lenho, onde se notam placas de perfuração (PS) simples e oblíquas dos elementos de vaso estreitos. Figuras 5-7. Elementos de vaso dissociados, estreitos e com paredes irregulares. Figura 8. Seção longitudinal radial do lenho, onde se observam pontoações intervasculares alternas (PT), de contorno poligonal (Barras figuras: $1=2 \mathrm{~mm} ; 2=200 \mu \mathrm{m} ; 3=100 \mu \mathrm{m} ; 4=25 \mu \mathrm{m} ; 5-7=50 \mu \mathrm{m} ; 8=50 \mu \mathrm{m}$ ). 
subdivididas, constituindo séries cristalíferas de até 21 câmaras (Fig. 9). Algumas células de parênquima podem apresentar paredes irregulares.

Os raios são unisseriados e bisseriados, raramente trisseriados; alguns raios bisseriados têm porções unisseriadas (Fig. 10). Homogêneos, constituídos por células quadradas (Fig. 11), ou heterogêneos, com células eretas e procumbentes. Algumas células radiais podem acumular substâncias fenólicas e cristais de oxalato de cálcio (Fig. 11).

Ocorrem fibras libriformes e fibrotraqueídes, assim como fibras septadas.
Foi evidenciada a presença abundante de amido, que pode ser encontrado nas fibras septadas, no parênquima apotraqueal, no parênquima radial e no parênquima medular das massas xilemáticas.

Os dados relativos às medições dos elementos celulares do xilema secundário encontram-se discriminados na Tab. 1.

No floema secundário, é geralmente nítida a delimitação entre o floema não-condutor e o condutor (Fig. 12-13). No floema condutor, os elementos de tubo crivado tendem a se organizar radialmente, e, em seção transversal, apresentam formato circular
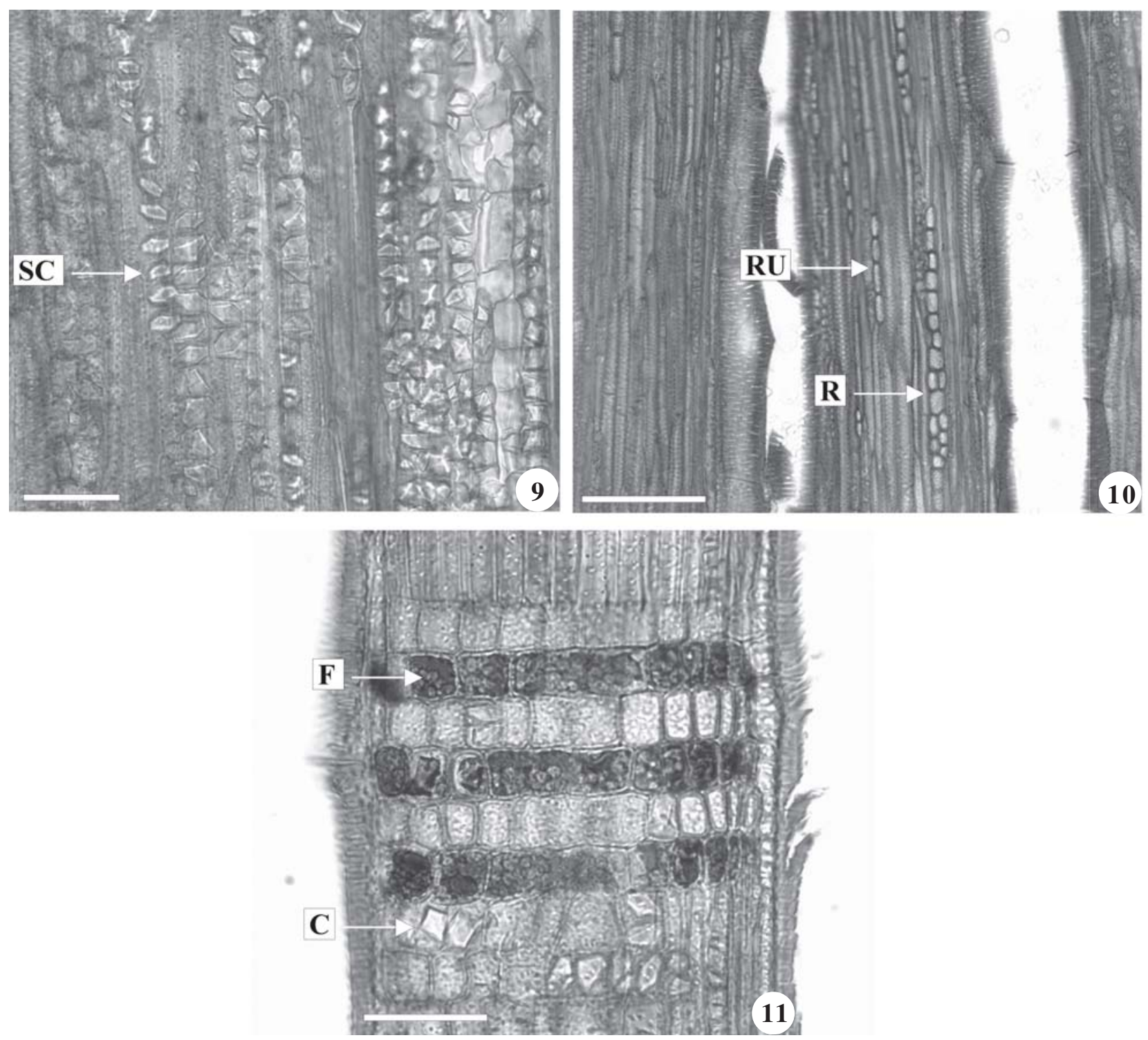

Figura 9. Seção longitudinal tangencial do lenho, evidenciando séries cristalíferas (SC). Figura 10. Seção longitudinal tangencial do lenho, onde se observam raios unisseriados (RU) e raio bisseriado com porção unisseriada (R). Figura 11. Seção longitudinal radial do lenho, onde se nota raio composto por células quadradas, algumas das quais portadoras de conteúdo fenólico (F) e outras, cristais prismáticos (C). (Barras figuras: $9,11=50 \mu \mathrm{m} ; 10=100 \mu \mathrm{m}$ ). 
Tabela 1. Dados quantitativos referentes aos elementos celulares do lenho de Serjania corrugata Radlk.

\begin{tabular}{lc}
\hline Características & Valores \\
\hline Diâmetro dos elementos de vaso largos & $66-157 \mu \mathrm{m}$ \\
Comprimento dos elementos de vaso largos & $(169-) 207(-254) \mu \mathrm{m}$ \\
Espessura da parede dos elementos de vaso largos & $(6-) 8(-11) \mu \mathrm{m}$ \\
Diâmetro dos elementos de vaso intermediários & $32-55 \mu \mathrm{m}$ \\
Comprimento dos elementos de vaso intermediários & $(151-) 179(-204) \mu \mathrm{m}$ \\
Espessura da parede dos elementos de vaso intermediários & $(3-) 4(-7) \mu \mathrm{m}$ \\
Diâmetro dos elementos de vaso estreitos & $8-23 \mu \mathrm{m}$ \\
Comprimento dos elementos de vaso estreitos & $(207-) 259(-324) \mu \mathrm{m}$ \\
Espessura da parede dos elementos de vaso estreitos & $(2-) 3(-4) \mu \mathrm{m}$ \\
Comprimento das fibras & $(263-) 343(-647) \mu \mathrm{m}$ \\
Diâmetro das fibras & $(9-) 15(-22) \mu \mathrm{m}$ \\
Espessura da parede das fibras & $(4-) 6(-9) \mu \mathrm{m}$ \\
Frequiência dos raios & $(1-) 3(-6) \mathrm{mm}$ \\
Altura dos raios & $(70-) 162(-388) \mu \mathrm{m}$ \\
Largura dos raios & $(6-) 13(-30) \mu \mathrm{m}$
\end{tabular}

ou oval. As placas crivadas são geralmente simples (Fig. 14), de horizontais a pouco inclinadas, ocorrendo raramente placas inclinadas do tipo escalariforme ou reticulado. As áreas crivadas laterais são abundantes (Fig. 15-16). O parênquima axial é difuso em agregados ou forma séries radiais; cristais prismáticos (geralmente justapostos) de oxalato de cálcio, ocorrem em células subdivididas, constituindo longas séries cristalíferas (Fig. 15), presentes também no floema não-condutor.

No floema não-condutor, observam-se células de esclerênquima (fibras, esclereides e parênquima lignificado), que nas porções mais internas do floema não-condutor encontram-se solitárias ou em grupos tangenciais de até 15 elementos, e nas porções mais externas, próximo ao córtex, estão organizadas em anel tangencial, mais ou menos contínuo, de 3-8 estratos celulares (Fig. 13).

Os raios têm percurso irregular, dilatando-se no floema não-condutor ou, eventualmente, a partir do floema condutor. São unisseriados ou bisseriados, raramente com porções trisseriadas, compostos por células quadradas, eretas e procumbentes (Fig. 17).

No córtex, podem estar presentes fragmentos do anel de fibras pericíclicas (de origem primária), que são eventualmente descartados pela periderme.

A periderme é única e apresenta felema compacto, com células uniformemente espessadas, que podem acumular substâncias fenólicas (Fig. 18). A feloderme apresenta cerca de 1-3 estratos de células parenquimáticas.

\section{Discussão}

Em Sapindaceae, é comum a ocorrência de placas de perfuração simples, pontoações alternas, coalescentes, raio-vasculares semelhantes às intervasculares, e depósitos nos vasos (Metcalfe \& Chalk 1950). Porosidade difusa, elementos de vaso de diâmetros distintos, elementos de vaso largos solitários ou em pares tangenciais, elementos de vaso estreitos em múltiplos radiais de até 20 elementos e raios heterogêneos são distintivos do gênero Serjania (Heimsch 1942; Klaassen 1999). Embora Klaassen (1999) tenha determinado quatro tipos anatômicos de lenho para a família Sapindaceae, as características observadas em $S$. corrugata não se encaixam em nenhum desses quatro tipos.

Em caules de lianas desprovidos de ramos vegetativos ou reprodutivos, como é o caso do material botânico utilizado comercialmente, o tipo de variação cambial presente é uma característica fundamental, visto que muitas são características de certos grupos taxonômicos. Quatro dos cinco tipos de variação cambial ocorrentes em Sapindaceae são exclusivas desta família (Schenck 1893; Metcalfe 1983). O tipo massa xilemática composta caracteriza-se por cilindros vasculares dispostos ao redor de um cilindro vascular central e ocorre em Serjania e Paullinia (Radlkofer 1892; Schenck 1893; Metcalfe 1983). O tipo massa xilemática dividida difere da massa xilemática composta por possuir de cinco a sete cilindros vasculares dispostos radialmente, sem a presença de um cilindro 

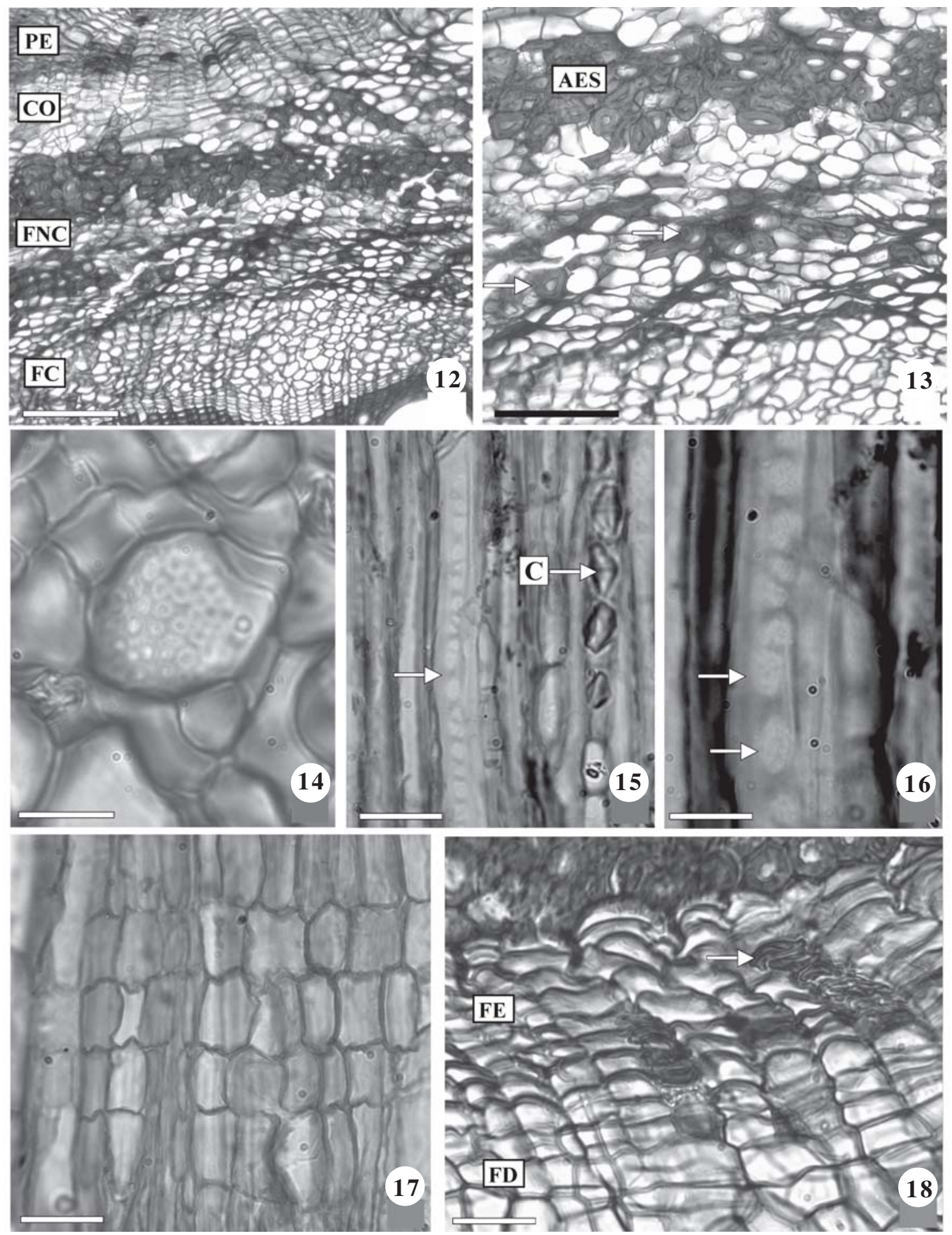

Figura 12. Seção transversal do caule, evidenciando a organização da casca em floema condutor (FC), floema não-condutor (FNC), córtex (CO) e periderme (PE). Figura 13. Detalhe do floema não-condutor, onde células de esclerênquima encontram-se solitárias (setas) ou em pequenos grupos nos estratos mais internos e formam um anel na porção mais externa (AES). Figura 14. Placa crivada simples observada em seção transversal. Figura 15. Seção longitudinal tangencial do floema secundário, onde se observam elemento de tubo crivado (seta) com áreas crivadas laterais abundantes, e série cristalífera (C). Figura 16. Detalhe da figura anterior, evidenciando as áreas crivadas laterais (setas) do elemento de tubo crivado. Figura 17. Raio do floema secundário, composto por células quadradas e eretas, visto em seção longitudinal radial. Figura 18. Detalhe da periderme, vista em seção transversal. Algumas células do felema armazenam substâncias fenólicas (seta). FD = Feloderme; FE = Felema. (Barras figuras: $12=300 \mu \mathrm{m} ; 13=150 \mu \mathrm{m} ; 14=15 \mu \mathrm{m} ; 15,17,18=30 \mu \mathrm{m} ; 16=10 \mu \mathrm{m}$ ). 
vascular central, e ocorre apenas nas oito espécies do "grupo de S. paradoxa" sensu Acevedo-Rodríguez (1991): S. paradoxa Radlk., S. corrugata, S. elegans Cambess., S. deflexa Gardner, S. paleata Radlk., S. magnistipulata Acev.-Rodr., S. lancistipula Acev.-Rodr. e S. erythrocaulis Acev.-Rodr. \& Somner. A variação do tipo massa xilemática cordada ocorre em Thinouia e Paullinia, e a massa xilemática separada ocorre em Urvillea e S. piscatoria (Schenck 1893; Metcalfe 1983). Estas últimas duas variações também se caracterizam pela presença de mais de um cilindro vascular, porém estes cilindros originam-se de forma distinta das demais variações cambiais ocorrentes em Sapindaceae.

De acordo com Carlquist (1985), pouca atenção tem sido dada à composição celular do xilema secundário das lianas. Em relação às lianas de Sapindaceae, descrições anatômicas do lenho são escassas. Heimsch (1942) e Klaassen (1999) descreveram anatomicamente o lenho de gêneros lianescentes da família, mas não apresentaram descrições individuais das espécies. Araque et al. (2000) descreveram o lenho de S. pyramidata Radlk. O floema secundário das lianas de Sapindaceae tem sido ainda menos estudado do que o lenho, não tendo sido encontrado nenhum trabalho referente ao assunto na literatura consultada.

Comparando anatomicamente a descrição do lenho de $S$. corrugata e $S$. pyramidata, nota-se que é possível distinguir as duas espécies. Diferentemente do que ocorre em $S$. corrugata, $S$. pyramidata não possui fibras septadas, traqueídes vasicêntricas e faixas de parênquima apotraqueal não-lignificado (Araque et al. 2000). Além disso, em S. pyramidata ocorrem células de parênquima radial disjuntivas, o que não foi observado em $S$. corrugata.

A presença de fragmentos do anel de fibras pericíclicas, de origem primária, pôde ser constatada através do estudo do desenvolvimento do caule, feito por Araújo \& Costa (2006).

Schenck (1893) e Haberlandt (1928) foram dois dos primeiros investigadores a afirmar que disposição "anômala" dos tecidos secundários pode aumentar a flexibilidade dos caules lianescentes, aumentando sua resistência a danos mecânicos causados por dobramentos e torções. Putz \& Holbrook (1991) conduziram experimentos biomecânicos em caules de plantas lianescentes e arborescentes, comparando os resultados para os dois hábitos. Os caules das lianas apresentaram maior flexibilidade e capacidade de torção, o que, segundo os autores, está intimamente relacionado com a anatomia interna. A ocorrência de cilindros separados, como em $S$. corrugata, resulta numa estrutura em cabo que, segundo Obaton (1960); Putz \& Holbrook (1991) e Acevedo-Rodríguez (1993), permite aliar resistência à flexibilidade. Fisher \& Ewers (1991) demonstraram que este arranjo de tecidos permite que o caule sofra apenas quebras longitudinais ordenadas, seguindo o sentido das forças de torção e deixando o xilema praticamente intacto.

A presença de vasos de diferentes diâmetros é relativamente comum em plantas de hábito lianescente (Carlquist 1985; 1991). Vasos de grande calibre possibilitam maior fluxo de água (Carlquist 1985), visto que a taxa de condução é diretamente proporcional à quarta potência do raio do elemento condutor (Hopkins 1999); entretanto, vasos de grande calibre são mais suscetíveis ao embolismo, assim como menos capazes de repará-los, se comparados a vasos de menor diâmetro e a traqueídes (Carlquist 1985; Ewers 1985; Ewers et al. 1997). A ocorrência simultânea de vasos de menor calibre confere segurança ao sistema vascular, pois continuam a conduzir água enquanto os de maior calibre estão embolisados (Baas \& Schweingruber 1987; Carlquist 1991). Portanto, a presença de vasos de diferentes diâmetros combina a eficiência de vasos largos com a segurança de vasos estreitos (Baas \& Schweingruber 1987). A presença de traqueídes vasicêntricas também garante maior segurança na condução, uma vez que estes elementos são menos vulneráveis ao embolismo, devido ao seu pequeno calibre. De acordo com Carlquist (1985), traqueídes vasicêntricas oferecem um sistema condutor subsidiário ideal em caso de embolismo de vasos em dicotiledôneas lenhosas.

Em Serjania corrugata ocorrem placas de perfuração simples, o que está relacionado com o aumento da eficiência de condução dos elementos de vaso, visto que este tipo de placa oferece menos resistência ao fluxo de água (Carlquist 1991). A ocorrência de faixas de parênquima apotraqueal nãolignificado pode estar relacionada à regeneração de injúrias (Fisher \& Ewers 1989; 1991; Carlquist 2001), ao aumento da flexibilidade do caule e ao armazenamento de amido (Schenck 1893; Carlquist 2001). A presença abundante de amido sugere duas hipóteses: a ligação a fluxos de crescimento e de floração e frutificação (Carlquist 1985; 1991; 2001; Mooney \& Gartner 1991), e também o reparo de tecidos injuriados (Mooney \& Gartner 1991). Uma terceira hipótese seria a recuperação de vasos embolisados: segundo Carlquist (1991) e Mooney \& 
Gartney (1991), o amido pode ser hidrolisado em açúcar, que, uma vez carreado para os vasos, aumentaria a pressão osmótica, recuperando assim o fluxo de água.

Os resultados aqui apresentados mostram características, tanto do xilema quanto do floema secundários, com potencial para identificação taxonômica, podendo assim auxiliar na fiscalização do uso comercial do caule desta espécie.

\section{Agradecimentos}

Os autores agradecem ao Conselho Nacional de Pesquisas (CNPq) e à Coordenadoria de Aperfeiçoamento de Pessoal de Nível Superior (CAPES), pelas bolsas concedidas durante o período de estudos; ao Programa Mata Atlântica e à Fundação Botânica Margaret Mee, pelo apoio financeiro; à Dra. Cátia H. Callado, pela revisão do manuscrito.

\section{Referências bibliográficas}

Acevedo-Rodríguez, P. 1990. Distributional patterns in brazilian Serjania (Sapindaceae). Acta Botanica Brasilica 4: 69-82.

Acevedo-Rodríguez, P. 1991. Serjania lancistipula (Sapindaceae), a new species from Bahia, Brazil. Brittonia 43: 165-167.

Acevedo-Rodríguez, P. 1993. Systematics of Serjania (Sapindaceae). Part I: a revision of Serjania sect. Platycoccus. Memoires of The New York Botanical Garden 67: 1-93.

Acevedo-Rodríguez, P. \& Somner, G.V. 2001. Two new species of Serjania (Sapindaceae) from southeastern Brazil. Brittonia 53: 477-481.

Araque, O.Z.; Espinoza de Pernía, N. \& León Hernández, W.J. 2000. Estudio anatómico del leño de seis especies de lianas. Revista Forestal Venezuelana 44(2): 39-48.

Araújo, G.U.C. \& Costa, C.G. 2006. Cambial variant in the stem of Serjania corrugata (Sapindaceae). IAWA Journal 27 (3): 269-280.

Baas, P. \& Schweingruber, F.H. 1987. Ecological trends in the wood anatomy of trees, shrubs and climbers from Europe. IAWA Bulletin new series 8: 245-274.

Bamber, R.K. \& Ter Welle, B.J.H. 1994. Adaptative trends in the wood anatomy of lianas. In: M. Iqbal (ed.). Growth patterns in vascular plants. Portland, Oregon, Dioscorides Press.

Barroso, G.M.; Peixoto, A.L.; Ichaso, C.L.F.; Costa, C.G.; Guimarães, E.F. \& Lima, H.C. 1991. Sistemática de Angiospermas do Brasil. v.2. Viçosa, Universidade Federal de Viçosa, Imprensa Universitária.
Carlquist, S. 1985. Observations on functional wood histology of vines and lianas: vessel dimorphism, tracheids, vasicentric tracheids, narrow vessels, and parenchyma. Aliso 11: 139-157.

Carlquist, S. 1991. Anatomy of vine and liana stems: a review and synthesis. In: F.E. Putz \& H.A. Mooney (eds.). The Biology of Vines. Cambridge, Cambridge University Press.

Carlquist, S. 2001. Comparative wood anatomy: systematic, ecological and evolutionary aspects of dicotyledon wood. $2^{\text {nd }}$ ed. Berlin, Springer Verlag.

Ewers, F.W. 1985. Xylem structure and water conduction in conifer trees, dicot trees, and lianas. IAWA Bulletin new series 6: 309-371.

Ewers, F.W.; Carlton, M.R.; Fisher, J.B.; Kolb, K.J. \& Tyree, M.T. 1997. Vessel diameters in roots versus stems of tropical lianas and other growth forms. IAWA Journal 18(3): 261-279.

Fisher, J.B. \& Ewers, F.W. 1989. Wound healing in stems of lianas after twisting and girdling injuries. Botanical Gazette 150: 251-265.

Fisher, J.B. \& Ewers, F.W. 1991. Structural responses to stem injuries in vines. In: F.E. Putz \& H.A. Mooney (eds.). The Biology of Vines. Cambridge, Cambridge University Press.

Guarim Neto, G.; Santana, S.R. \& Silva, J.V.B. 2000. Notas etnobotânicas de Sapindaceae Jussieu. Acta Botanica Brasilica 14(3): 327-334.

Haberlandt, G. 1928. Physiological plant anatomy. London, MacMillan and Co. Limited, St. Martin Street.

Heimsch, C. 1942. Comparative anatomy of the secondary xilem in the "Gruinales" and "Terebinthales", of Wettstein, with reference to taxonomic grouping. Lilloa 8: 83-197.

Hopkins, W.G. 1999. Introduction to plant physiology. $2^{\text {nd }}$ ed. New York, John Wiley \& Sons.

IAWA Committee. 1989. IAWA list of microscopic features for hardwood identification. IAWA Bulletin 10: 219-332.

Johansen, D.A. 1940. Plant microtechnique. New York, McGraw-Hill Book Co. Inc.

Klaassen, R. 1999. Wood anatomy of the Sapindaceae. IAWA Journal Supplement 2.

Kraus, J.E. \& Arduin, M. 1997. Manual básico de métodos em morfologia vegetal. Rio de Janeiro, Editora EDUR.

Metcalfe, C.R. 1983. Anomalous structure. In: C.R. Metcalfe \& L. Chalk. Anatomy of the Dicotyledons. $2^{\text {nd }}$ ed. Oxford, Clarendon Press.

Metcalfe, C.R. \& Chalk, L. 1950. Anatomy of the Dicotyledons. v.I. Oxford, Clarendon Press.

Mooney, H.A. \& Gartner, B.L. 1991. Reserve economics of vines. In: F.E. Putz \& H.A. Mooney (eds.). The Biology of Vines. Cambridge, Cambridge University Press.

Obaton, M. 1960. Les lianes ligneuses à structure anormale des forêtes denses d'Afrique Ocidentale. Annales des Sciences Naturelles, Botanique et Biologie Végétal série 12(1): 1-220.

Putz, F.E. 2006. Vine ecology. Ecology.info 24. 
Putz, F.E. \& Holbrook, N.M. 1991. Biomechanical studies of vines. In: F.E. Putz \& H.A. Mooney (eds.). The Biology of Vines. Cambridge, Cambridge University Press.

Radlkofer, L. 1892. Sapindaceae. In: C.F.P. Martius \& A.G. Eichler. Flora brasiliensis, v.8, parte 3 .

Richter, H.G.; Mazzoni-Viveiros, S.C.; Alves, E.S.; Lucchi, A.E. \& Costa, C.G. 1996. Padronização de critérios para descrição anatômica da casca: lista de características e glossário de termos. IF Série Registros 16: 1-25.
Rupp, P. 1964. Polyglycol als Einbettungsmedium zum Schneiden botanischer Preparate. Mikrokosmos 3:123-128. Schenck, H. 1893. Beiträge zur Biologie und Anatomie der Lianen, im Besonderon der in Brasilien einheimischen Arten. Beiträge zur anatomie der lianen. In: A.F. Schimper (ed.). Botanische Mittheilungen aus den Tropen 5. Gustav Fischer, Jena.

Strasburger, E. 1924. Handbook of practical botany for the botanical laboratory and private student. $8^{\text {th }} \mathrm{ed}$. London, George Allen \& Unwin, Ltd. 